\title{
Short-term dietary selenium restriction in young adults: quantitative studies with the stable isotope ${ }^{74} \mathrm{SeO}_{3}{ }^{2-}$
}

\author{
BY LYNDA J. KASPER, ${ }^{1}$ VERNON R. YOUNG ${ }^{1}$ \\ AND MORTEZA JANGHORBANI ${ }^{1,2 * \dagger}$ \\ ${ }^{1}$ Laboratory of Human Nutrition, Department of Nutrition and Food Science \\ and ${ }^{2}$ Nuclear Reactor Laboratory, Massachusetts Institute of Technology, Cambridge, \\ Massachusetts 02139, USA
}

(Received 16 November 1983 - Accepted 25 May 1984)

1. A $45 \mathrm{~d}$ metabolic study was carried out in four young adult male North American residents consuming a controlled diet based on an amino acid mixture. During the initial $10 \mathrm{~d}$, total daily selenium intake was adjusted to 107.7 (SE 0.1) $\mu \mathrm{g} / \mathrm{d}$, which was reduced to 11.4 (SE 0.1$) \mu \mathrm{g} / \mathrm{d}$ for the remaining $35 \mathrm{~d}$.

2. Two doses of a stable isotope $\left({ }^{4} \mathrm{SeO}_{3}{ }^{2-}\right)$ were administered orally in the post-absorptive state on days 4 and 39 of the study.

3. Se balance (faecal + urinary excretion) as well as stable isotope excretion studies were carried out for the entire $45 \mathrm{~d}$ period; blood plasma and erythrocyte Se concentrations were also monitored.

4. Plasma Se concentrations $(\mu \mathrm{g} / \mathrm{ml}$ ) fell progressively from the initial value of 0.132 (SE 0.007 ) to 0.083 (SE 0.008 ) at the end of the study. The erythrocyte concentrations of Se did not vary in a consistent manner (average value for the entire study 0.147 (SE 0.002$) \mu \mathrm{g} / \mathrm{ml}$ ).

5. Faecal excretion of unenriched Se decreased from 66 (SE 6) $\mu \mathrm{g} / \mathrm{d}$ for days $1-10$ to $10 \cdot 2$ (SE $0 \cdot 8$ ) $\mu \mathrm{g} / \mathrm{d}$ for days 14-40. Mean urinary excretions of the unenriched Se were 43.9 (SE 2.8) $\mu \mathrm{g} / \mathrm{d}$ (days I-10) and 26.9 (SE 4.6) $\mu \mathrm{g} / \mathrm{d}$ (days 1440 ). Total balance (intake - faecal excretion-urinary excretion) for unenriched Se was $(\mu \mathrm{g} / \mathrm{d}):-18$ (SE 7) days 10-19, -17 (SE 2) days 19-39, -5 (SE 1) days 38-45.

6. Fractional absorption of the ingested label was 0.529 (SE 0.032) and 0.542 (SE 0.038) for the Se-adequate and Se-restricted phases of the study. However, urinary excretion of the absorbed label was reduced from 6.57 (SE 0.73 ) \% for day I of the Se-adequate phase to only 3.32 (SE 0.26 ) \% for day 1 of the Se-restricted phase. Similar observations were also made for day 7 of each phase.

7. These findings indicate that immediate contribution of ingested Se to the urinary Se pool is small.

Average intakes for selenium among populations in different parts of the world may vary by an order of magnitude (Thomson \& Robinson, 1980). Despite this wide range of intake and the essential nature of the micronutrient, deficiencies have not been established unequivocally in human subjects (Young et al. 1982), except perhaps in reference to the aetiology of Keshan disease (Chen et al. 1981). An adequate judgement of the nutritional and health significance of widely differing habitual intakes of Se requires a better understanding of the physiology of human Se metabolism and, in this context, there is little reliable information available on the human body Se content. However, the published literature indicates that North American adults could contain three to four times the amount of this mineral as compared with that in New Zealanders (Schroeder et al. 1970; Stewart et al. 1978). Levander et al. (1981) recently reported a study on Se balance in young adult Americans following short-term dietary Se restriction (45 d) and they have documented the changes in faecal and urinary Se losses that occurred under these conditions. Despite the importance of their study, a number of questions related to homeostasis of Se remain unanswered by the metabolic balance approach. Thus, we have conducted a comparable investigation but with inclusion of isotopic-tracer studies, employing our recently developed method using the stable isotope ${ }^{74} \mathrm{SeO}_{3}{ }^{2-}$ (Janghorbani et al. $1981 a, b$ ).

* For reprints.

$\dagger$ Present address: Boston University School of Medicine, 85 East Newton Street M1008, Boston, Massachusetts 02118 , USA. 


\section{EXPERIMENTAL \\ Metabolic study}

Four healthy male MIT students (age 19-20 years; weight 63-74 kg) participated in the study on an out-patient basis at the MIT Clinical Research Center. Before the study, their good health was confirmed by physical examination, including a complete medical history and screening blood tests. Throughout the study, they were examined weekly by the attending physician; they each kept a diary and their body-weight was constant to within $\pm 2 \mathrm{~kg}$. The study procedure received the approval of the MIT Committee on the Use of Humans as Experimental Subjects, and the Policy Committee of the Clinical Research Center.

The study lasted for $45 \mathrm{~d}$ during which the subjects consumed a nutritionally complete diet (except as noted for $\mathrm{Se}$ ) based on an amino acid mixture. Additional energy was provided with protein-free cookies, pudding, butter and sweetened beverages. The meals were consumed in four equal portions daily in the departmental metabolic kitchen under the supervision of a trained dietitian, with vitamin and mineral supplements taken only with breakfast. The composition of the daily diet is given in Table 1 . The $45 \mathrm{~d}$ study consisted of two diet periods: (a) Se-replete period (days 1-10) during which the mineral supplement included $100 \mu \mathrm{g} \mathrm{Se} / \mathrm{d}$ as sodium selenite increasing total Se intake to $107 \cdot 7$ (SE $0 \cdot 1$ ) $\mu \mathrm{g} / \mathrm{d}$ (Table 1), and (b) Se-restriction period (days 11-45) during which no supplemental Se was given so that total Se intake was 11.4 (SE 0.1$) \mu \mathrm{g} / \mathrm{d}$. On day 4 of the study, Se from the mineral supplement was excluded and instead a single solution of enriched ${ }^{74} \mathrm{Se}$ as $\mathrm{H}_{2}{ }^{74} \mathrm{SeO}_{3}$ $\left({ }^{74} \mathrm{Se} 108 \cdot 8 \mu \mathrm{g}\right.$, total Se $200 \mu \mathrm{g}$ ) was given under fasting conditions at 08.00 hours. No food was consumed for the next $4 \mathrm{~h}$. This dosing procedure was repeated on day 39 also. At the time of administration of the selenite label a separate aqueous solution of the stable isotope ${ }^{65} \mathrm{Cu}$ as ${ }^{65} \mathrm{CuCl}_{2}$ providing $2.02 \mathrm{mg}$ total $\mathrm{Cu}$ was also consumed. The results from this aspect of the experiment will be reported separately.

Venous blood samples were drawn initially and regularly throughout the study in trace-metal-free non-heparinized syringes with EDTA added as anticoagulant. Blood was centrifuged for $15 \mathrm{~min}$ at $3000 \mathrm{rev} . / \mathrm{min}$ and plasma decanted immediately into precleaned polyethylene 'snap-cap' vials and frozen. Erythrocytes were also frozen until used for analyses.

Urine was collected daily in plastic bottles containing $15 \mathrm{ml}$ hydrochloric acid (300 ml/l), the volume was measured accurately and a subsample frozen for isotopic analyses. Complete collections of stools were made, on a daily basis, in plastic cups and frozen for isotopic analyses.

\section{Sample preparation and isotopic analyses}

Frozen plasma samples were allowed to thaw and $1 \mathrm{ml}$ portions were accurately transferred to beakers for wet ashing. Frozen erythrocytes were weighed, lyophilized, and accurately weighed subsamples were taken for wet ashing. Portions from daily urine collections were measured volumetrically and analysed either individually or pooled on a 3-4d basis before wet ashing. Faecal samples were either homogenized individually with deionized water and subsamples taken for analyses or were homogenized on a 4-d pooled basis and portions retained for analyses.

Each sample was analysed for two stable isotopes $\left({ }^{74} \mathrm{Se}\right.$ and $\left.{ }^{76} \mathrm{Se}\right)$ using the method of radiochemical neutron activation analysis developed especially for this purpose (Janghorbani et $a l .1981 \mathrm{~b}$ ). The method is briefly as follows.

The sample was spiked with high-specific-activity ${ }^{75} \mathrm{Se}$ radiotracer, wet ashed either by the nitric acid and hydrogen peroxide method (all samples except urine; Janghorbani et al. 
Table 1. Diet composition and daily consumption*

(Mean values with 1 standard error for four to eight samples)

\begin{tabular}{|c|c|c|c|}
\hline & \multirow[b]{2}{*}{ Food consumption $(\mathrm{g} / \mathrm{d})$} & \multicolumn{2}{|c|}{ Selenium content $(\mu \mathrm{g} / \mathrm{g})$} \\
\hline & & Mean & S.E. \\
\hline Amino acid mixture & $60 \cdot 3-71 \cdot 0$ & $0 \cdot 0175$ & 0.002 \\
\hline Cookies & 244 & 0.0124 & 0.004 \\
\hline Pudding & $493-654$ & $0 \cdot 00237$ & 0.001 \\
\hline Butter & 28 & & \\
\hline \multirow[t]{2}{*}{ Kool aid } & $1421-1472$ & 0.00112 & 0.0006 \\
\hline & Energy distribution $(\%)$ & & \\
\hline Protein $(50-60 \mathrm{~g})$ & $6 \cdot 4-7 \cdot 1$ & & \\
\hline Fat $(115-127 \mathrm{~g})$ & $34 \cdot 4-34 \cdot 6$ & & \\
\hline Carbohydrate $(440-487 \mathrm{~g})$ & $58 \cdot 5-59 \cdot 0$ & & \\
\hline
\end{tabular}

* Daily vitamin and mineral supplements: retinol $1500 \mu \mathrm{g} \mathrm{DL}-\alpha$-tocopherol $15 \mathrm{mg}$, ascorbic acid $60 \mathrm{mg}$, folic acid $0.4 \mathrm{mg}$, thiamin $1.5 \mathrm{mg}$, riboflavin $1.7 \mathrm{mg}$, niacin $20 \mathrm{mg}$, pyridoxine $2 \mathrm{mg}$, cyanocobalamin $6 \mu \mathrm{g}$, cholecalciferol $10 \mu \mathrm{g}$, iron $18 \mathrm{mg}$ (all as One-A-Day vitamins plus iron; Miles Laboratories, Inc., Elkhart, IN 46515); pantothenic acid $12.5 \mathrm{mg}$ (calcium D-pantothenate; W. T. Thompson Co., Carson, CA 90745); choline $500 \mathrm{mg}$ (choline bitartrate; Plus Products, Irvine, CA); zinc $20 \mathrm{mg}$ (gluconate tablets; Lee Nutrition, Inc., Cambridge, MA 02142); calcium $928 \mathrm{mg}$, phosphorus $720 \mathrm{mg}$ (Dical-D-Wafers; Abbott Laboratories, North Chicago, IL 60064); potassium $75 \mathrm{mmol}$ (k-Lyte tablets); magnesium as $\mathrm{MgO} 398 \mathrm{mg}$; copper as $\mathrm{CuCl}_{2} .2 \mathrm{H}_{2} \mathrm{O} 2 \mathrm{mg}$; manganese as $\mathrm{MnSO}_{4} .2 \mathrm{H}_{2} \mathrm{O} 1.66 \mathrm{mg}$; molybdenum as $\mathrm{Na}_{2} \mathrm{MoO}_{4} .2 \mathrm{H}_{2} \mathrm{O} 0.083 \mathrm{mg}$; chromium as $\mathrm{Cr}_{2}\left(\mathrm{SO}_{4}\right)_{3} .15 \mathrm{H}_{2} \mathrm{O} 0.168 \mathrm{mg}$; aluminium as $\mathrm{AlK}\left(\mathrm{SO}_{4}\right)_{2} .12 \mathrm{H}_{2} \mathrm{O} 1.61 \mathrm{mg}$; iodide as $\mathrm{KI} 0.29 \mathrm{mg}$.

$1981 b$ ) or by the perchloric acid and $\mathrm{HNO}_{3}$ method (urine; Janghorbani et al. 1982). Following complete oxidation of $\mathrm{Se}$ to $\mathrm{Se}(\mathrm{IV})-\mathrm{Se}(\mathrm{VI}), 50 \mathrm{ml}$ concentrated $\mathrm{HCl}$ was added and the mixture boiled to ensure complete conversion of any $\mathrm{Se}$ (VI) to $\mathrm{Se}$ (IV). Afterwards, solution $\mathrm{pH}$ was adjusted to $2 \cdot 0 \pm 0.1$ with sulphuric acid-ammonium hydroxide, and $\mathrm{Se}$ precipitated by addition of $2 \mathrm{ml}$ ammonium pyrrolidindithiocarbamate $(50 \mathrm{~g} / \mathrm{l})$. The precipitate was centrifuged and the supernatant fraction carefully poured off. The precipitate was then dissolved with approximately $2 \mathrm{ml}$ hot concentrated $\mathrm{HNO}_{3}$, the solution transferred to 2-ml irradiation vials and dried at $85^{\circ}$. Following complete drying, the vial was purged with nitrogen gas, a sample-restraining plug inserted and the cap heat-sealed. Chemical yield was measured by counting the radioactivity against appropriately prepared radiotracer standards. Appropriate Se standards were prepared from high-purity Se metal dissolved in concentrated $\mathrm{HNO}_{3}$, portions transferred to standard irradiation vials, dried, purged with $\mathrm{N}_{2}$ gas, plugged and sealed. Several blank samples were prepared in an identical manner, as were several subsamples from the National Bureau of Standards (NBS) standard reference material 1577 (bovine liver) for quality assurance.

All samples were first analysed for ${ }^{76} \mathrm{Se}$ employing the nuclear reaction ${ }^{76} \mathrm{Se}(n, \gamma){ }^{77 \mathrm{~m}} \mathrm{Se}$ (half life $\left(t_{1 / 2}\right) 17.6 \mathrm{~s}$, energy of gamma line $(\gamma) 160 \mathrm{keV}$ ) and subsequently re-irradiated for measurement of ${ }^{74} \mathrm{Se}$ based on the nuclear reaction ${ }^{74} \mathrm{Se}(n, \gamma){ }^{75} \mathrm{Se}\left(i_{1 / 2} 120 \mathrm{~d}, \gamma 265 \mathrm{keV}\right)$. Details of these procedures as well as their analytical characteristics have been given in detail previously (Janghorbani et al. 1981b).

\section{Chemicals}

All chemicals were of analytical reagent grade and used as purchased. Stable isotope ${ }^{74} \mathrm{Se}$ was purchased from Oak Ridge National Laboratory, Oak Ridge, TN (see Table 2 for isotopic composition) as metal powder. An accurately weighed quantity was dissolved in 
Table 2. Comparisons between isotopic composition of the enriched selenium solution and natural Se

\begin{tabular}{|c|c|c|}
\hline \multirow[b]{2}{*}{ Isotope } & \multicolumn{2}{|c|}{ Mass isotopic abundance $(\%)^{*}$} \\
\hline & Enriched & Natural \\
\hline${ }^{74} \mathrm{Se}$ & 54.43 & 0.815 \\
\hline${ }^{76} \mathrm{Se}$ & 9.198 & 8.66 \\
\hline${ }^{77} \mathrm{Se}$ & $4 \cdot 406$ & $7 \cdot 31$ \\
\hline${ }^{78} \mathrm{Se}$ & $10 \cdot 54$ & 23.21 \\
\hline${ }^{80} \mathrm{Se}$ & $17 \cdot 30$ & 50.65 \\
\hline${ }^{82} \mathrm{Se}$ & $4 \cdot 132$ & $9 \cdot 35$ \\
\hline
\end{tabular}

* Certified values are based on percentage atomic abundance; these values have been calculated based on certified atomic abundance and isotopic mass values.

a minimum volume of concentrated $\mathrm{HNO}_{3}$, with slight warming, until completely dissolved, and the solution diluted with deionized water to provide a suitable working solution; the $\mathrm{pH}$ was measured as 3 . This solution was stored in an acid-washed screw-cap polyethylene bottle.

\section{RESULTS AND DISCUSSION}

\section{Accuracy of stable-isotope measurements}

The isotopic procedure employed has been described in detail previously (Janghorbani et $a l 1981 \mathrm{~b}$ ) and applied in studies of the dynamics of selenite metabolism in healthy young men (Janghorbani et al. 1981 a). However, because this method has not yet been applied by others in human metabolic studies, we present values explicitly for the evaluation, by others, of its accuracy. The accuracy of the overall analytical method was evaluated by several procedures: (1) measurement of Se isotope ratios in unenriched samples (2) comparisons of Se content of the NBS standard reference material 1577 (bovine liver) (certified value $1 \cdot 1$ (SE $0 \cdot 1) \mu \mathrm{g} / \mathrm{g}$ ) and (3) measurements of plasma, erythrocytes and urinary Se concentrations of the subjects taking part in the present study. The results are summarized in Table 3. The measured isotope ratios for the four matrices of interest to the present study were (mean with SE): faeces $0.100(0.0039)$, plasma $0.0985(0.0046)$, urine $0.0907(0.0013)$, erythrocytes $0.1125(0.0027)$. The unenriched mass isotope ratio $\left({ }^{74} \mathrm{Se}:{ }^{76} \mathrm{Se}\right.$; MIR) is assumed to be 0.0941 (Table 2, Lederer et al. 1967). Comparison of these measured values with the assumed reference value of 0.0941 employing Student's $t$ test $\left(\mathrm{H}_{0}\right.$ : $\mu=0.0941)$ accepts the hypothesis for measurements on faeces and plasma $(\alpha 0.05)$, but not for erythrocytes and urine (for urine: $T 2 \cdot 6, t_{0 \cdot 025,8} 2 \cdot 306$ for erythrocytes: T $6 \cdot 8, t_{0 \cdot 025,5}$ 2.571 ). Thus it appears that for all the samples measured in the present study the precision of measurements falls within the expected value (coefficient of variation $10 \%$; Janghorbani et al. 1981 b). The absolute values of MIR for faeces and plasma were well within the accepted value of 0.0941 . However, small systematic errors appeared in the measurements carried out for erythrocytes and urine. The absolute value of the systematic errors for the urine $(0.0907-0.0941=0.0034)$ was $3.6 \%$ of the theoretical value, while that for erythrocytes was somewhat larger ( $20 \%$ of accepted value). The absolute accuracy of the measurements was also checked by analysis of NBS standard reference material 1577 (bovine liver) employing ${ }^{76} \mathrm{Se}$ as the measurement index. The measured value of 1.04 (SE 0.013) agreed well with the certified value of $1 \cdot 1($ SE $0 \cdot 1)$. The blank measurements carried out on equal portions of combined reagents indicated a residual level of 0.0054 (SE 0.0010) $\mu \mathrm{g}$, hence absence of a major problem with background level. 
Table 3. Values related to the accuracy of stable-isotope measurements

\begin{tabular}{|c|c|c|c|}
\hline & \multirow[b]{2}{*}{$n$} & \multicolumn{2}{|c|}{ Measured value* } \\
\hline & & Mean & $1 \mathrm{SEM}$ \\
\hline \multicolumn{4}{|l|}{ Natural ratios ${ }^{74} \mathrm{Se}:{ }^{76} \mathrm{Se}$ in: } \\
\hline Faeces & 7 & $0 \cdot 100$ & 0.0039 \\
\hline Plasma & 8 & 0.0985 & 0.0046 \\
\hline Erythrocytes & 6 & 0.1125 & 0.0027 \\
\hline Urine & 9 & 0.0907 & 0.0013 \\
\hline $\begin{array}{l}\text { Absolute accuracies }(\mu \mathrm{g} / \mathrm{g}) \text {; } \\
\text { NBS SRM } 1577(\text { bovine liver), } \\
\text { certified at } 1 \cdot 1(\text { SE } 0 \cdot 1)\end{array}$ & 14 & 1.04 & 0.013 \\
\hline Background levels ( $\mu \mathrm{g} /$ blank) & 7 & 0.00541 & 0.00102 \\
\hline $\begin{array}{l}\text { Blood indices: } \\
\text { Plasma }(\mu \mathrm{g} / \mathrm{ml}) \\
\text { Erythrocytes: } \mu \mathrm{g} / \mathrm{g} \text { freeze-dried wt } \\
\qquad \mu \mathrm{g} / \mathrm{ml}\end{array}$ & $\begin{array}{l}8 \\
6\end{array}$ & $\begin{array}{l}0 \cdot 132 \\
0 \cdot 478 \\
0 \cdot 147\end{array}$ & $\begin{array}{l}0.007 \\
0.031 \\
0.0095\end{array}$ \\
\hline \multicolumn{4}{|l|}{ Excretion indices $(\mu \mathrm{g} / \mathrm{d}$; days $1-10)$ : } \\
\hline Urine & & 43.9 & $2 \cdot 8$ \\
\hline Faeces & & $65 \cdot 8$ & $5 \cdot 6$ \\
\hline
\end{tabular}

NBS SRM, National Bureau of Standards standard reference material.

* Accepted natural isotope ratio: 0.0941.

An indirect estimate of the accuracy of these measurements is obtained by examination of the estimated values of blood and excretion indices in these subjects in comparison with the expected levels. In a recent study with six American adults, Levander et al. (1981) observed plasma Se concentrations of 0.136 (SE 0.015$) \mu \mathrm{g} / \mathrm{ml}$ at the start of a depletionrepletion study. Our measured values for plasma of 0.132 (SE 0.007) agree closely with their values. Dickson \& Tomlinson (1967) have reported values of $0 \cdot 144$ and $0.236 \mu \mathrm{g} / \mathrm{ml}$ respectively for plasma and erythrocytes of Canadians. Similarly, Levander et al. (1981) obtained values for daily urine and faecal Se excretion, at the start of the control-diet study, of 54 (SE 11) and 29 (SE 5) $\mu \mathrm{g} / \mathrm{d}$ respectively. Following a Se depletion phase, the subjects were given 204-224 $\mu \mathrm{g} \mathrm{Se} / \mathrm{d}$ from seleniferous wheat and tuna for $24 \mathrm{~d}$. Their daily urinary and faecal Se excretions rose and achieved a plateau level of 112 (SE 13) and 70-104 $\mu \mathrm{g} / \mathrm{d}$ respectively. Our subjects consumed 107.7 (SE 0.1) $\mu \mathrm{g} \mathrm{Se} / \mathrm{d}$, mostly as selenite, during the initial $10 \mathrm{~d}$ of the study. Their urinary and faecal excretions for this period, as measured by ${ }^{78} \mathrm{Se}$, amounted to (mean with SE) $43.9(2.8)$ and $65.8(5 \cdot 6) \mu \mathrm{g} / \mathrm{d}$ for a total daily excretion of $109 \cdot 7(6 \cdot 3) \mu \mathrm{g}$.

\section{Se balance}

Results for cumulative faecal and urinary excretion of Se, for each subject, are shown in Figs. 1 and 2 respectively. With ingestion of the low-Se diet, faecal excretion of the mineral decreased rapidly from a daily value of (mean with 1 SEM) $66(6) \mu \mathrm{g}$ to $10 \cdot 2(0.8) \mu \mathrm{g}$ during days 14-40. Urinary excretion also declined, but more gradually (Fig. 2). Mean (with SE) daily urinary excretion was $43.9(2 \cdot 7)$ for days $3-13$ and $26.9(4 \cdot 6)$ for days $14-40$. In a similar study, Levander et al. (1981) also observed a rapid decrease in faecal excretion, with a more gradual reduction for urinary Se output. The mean (with SE) daily urinary excretions for selected days of their study were $(\mu \mathrm{g} / \mathrm{d})$ : day $3,44 \cdot 4(6 \cdot 7)$; day $9,53 \cdot 1(8 \cdot 3)$; day $22,26.6$ (1.9); day $31,20.0(2 \cdot 0)$; day $36,18 \cdot 1(1 \cdot 7)$.

In the present study all cumulative urinary Se values for days 1-11 and days $21-39$ (see 


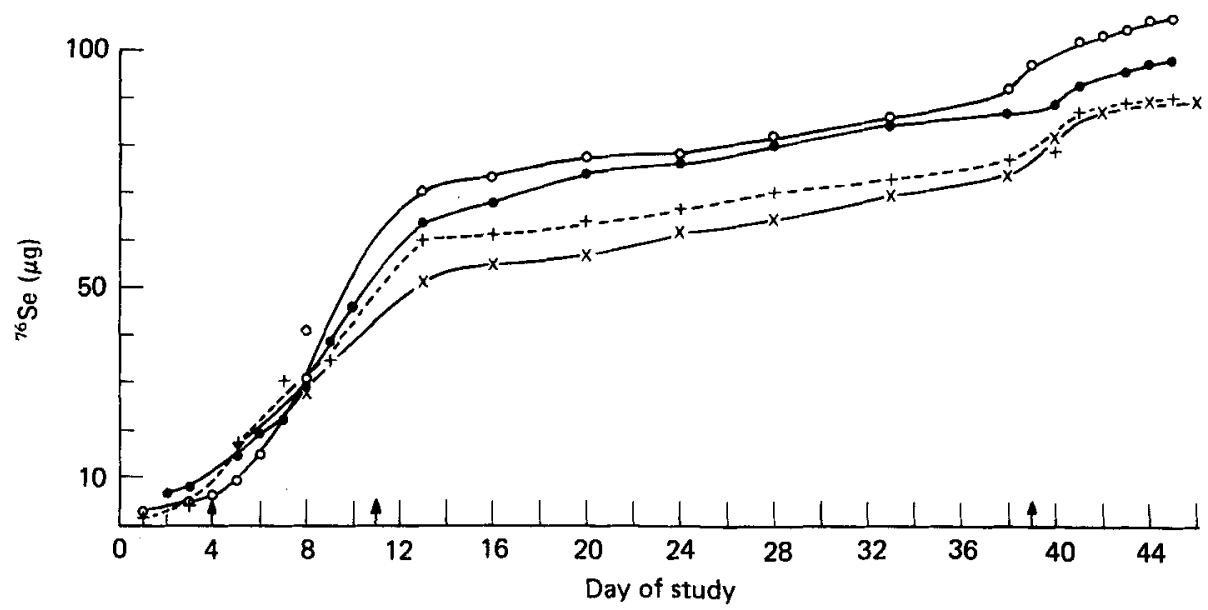

Fig. 1. Cumulative faecal excretion $\left(\mu \mathrm{g}^{76} \mathrm{Se}\right)$ of unenriched selenium in four $(0,0, x,+)$ adult male human subjects during periods of adequate- (days 1-10) and low- (days 11-45) Se intake. (To convert to total unenriched Se excretion, multiply by the factor 11.52.) Arrows indicate (from left to right): administration of first dose of ${ }^{74} \mathrm{Se}$, initiation of Se-restriction phase, administration of second dose of ${ }^{74} \mathrm{Se}$.

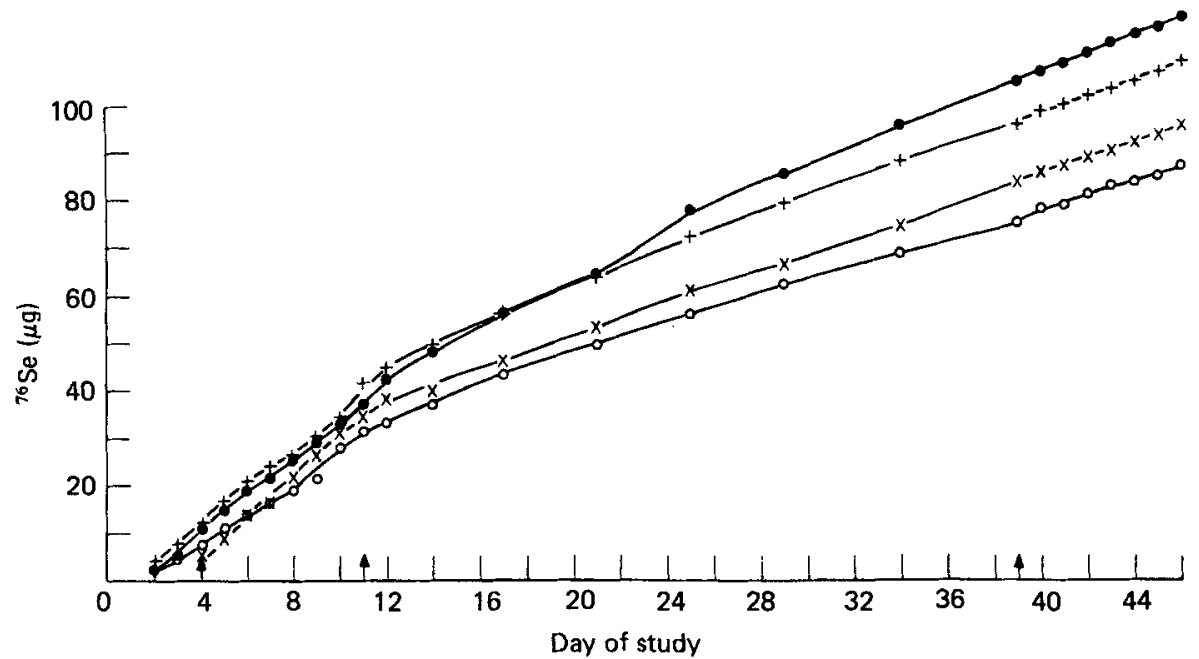

Fig. 2. Cumulative urinary excretion $\left(\mu \mathrm{g}^{76} \mathrm{Se}\right)$ of unenriched selenium in four $(0,0, x,+)$ adult male human subjects during periods of adequate- (days 1-10) and low- (days 11-45) Se intake. (To convert to total unenriched Se excretion, multiply by the factor 11.52.) Arrows indicate (from left to right): administration of first dose of ${ }^{74} \mathrm{Se}$, initiation of Se-restriction phase, administration of second dose of ${ }^{74} \mathrm{Se}$.

Fig. 2) in each subject were examined by least-squares linear equations and these results are summarized in Table 4 . The reason for selecting values for days 21-39 for the second period of the study was based on observations of Levander et al. (1981) that following institution of the low-Se regimen, about $12 \mathrm{~d}$ were required before the output of urinary Se appeared to stabilize. For values after day 39 (Fig. 2), introduction of a relatively large dose of labelled Se $(200 \mu \mathrm{g} \mathrm{Se})$ might have introduced a small perturbation in the rate of urinary excretion, although a visual examination of the cumulative plots indicates only a small effect. It should be noted here that because the balance results are based on analysis of ${ }^{76} \mathrm{Se}$ alone (and subsequent conversion to $\mathrm{Se}$ ), the results exclude the excreted component 
Table 4. Results of a linear regression analysis of daily urine selenium output in four adult male human subjects during periods of adequate-and low-Se intake

\begin{tabular}{|c|c|c|c|c|}
\hline \multirow{2}{*}{$\begin{array}{c}\text { Subject } \\
\text { no. }\end{array}$} & \multicolumn{2}{|c|}{ Adequate Se (days $1-11$ ) } & \multicolumn{2}{|c|}{ Low Se (days 2I-39) } \\
\hline & $r^{2}$ & $\operatorname{Rate}(\mu \mathrm{g} / \mathrm{d})$ & $r^{2}$ & Rate $(\mu \mathrm{g} / \mathrm{d})$ \\
\hline 01 & 0.998 & $49 \cdot 7$ & 0.997 & 18.9 \\
\hline 02 & 0.985 & $36 \cdot 6$ & 0.995 & $16 \cdot 1$ \\
\hline 03 & 0.998 & $44 \cdot 3$ & 0.985 & $25 \cdot 3$ \\
\hline 04 & 0.987 & $45 \cdot 0$ & 0.998 & $20 \cdot 3$ \\
\hline Mean (with SEM) & & $43.9(2.7)$ & & $20 \cdot 2(1 \cdot 9)$ \\
\hline
\end{tabular}

Table 5. Changes in body selenium balance in adult male human subjects during periods of adequate- and low-Se intake

\begin{tabular}{|c|c|c|c|c|c|c|c|}
\hline \multirow{2}{*}{$\begin{array}{l}\text { Day of } \\
\text { study* }\end{array}$} & \multicolumn{2}{|c|}{$\begin{array}{c}\text { Cumulative excretion } \\
\text { (faecal and urinary) }(\mu \mathrm{g})\end{array}$} & \multirow{2}{*}{$\frac{\begin{array}{c}\text { Cumulative } \\
\text { intake }(\mu \mathrm{g}) \dagger\end{array}}{\text { Mean }}$} & \multicolumn{2}{|c|}{$\begin{array}{c}\text { Total } \\
\text { balance }(\mu \mathrm{g})\end{array}$} & \multicolumn{2}{|c|}{$\begin{array}{l}\text { Balance for study } \\
\text { period }(\mu \mathrm{g} / \mathrm{d})\end{array}$} \\
\hline & Mean & $\mathrm{SE}$ & & Mean & $\mathrm{SE}$ & Mean & $\mathbf{S E}$ \\
\hline 10 & 909 & 29 & 1169 & +260 & 29 & & \\
\hline 19 & 1435 & 65 & 1272 & -163 & $65\}$ & 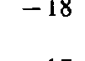 & 1 \\
\hline 38 & 1980 & 85 & 1488 & -492 & $85\}$ & -17 & 2 \\
\hline 45 & 2286 & 77 & 1756 & -530 & $\left.{ }_{77}\right\}$ & & \\
\hline
\end{tabular}

* Se restriction began on day 11.

$\dagger$ Includes Se intake from the labelled solution.

from the label (except for its ${ }^{76} \mathrm{Se}$ component) and this represents true balance of natural Se.

A summary of the changes in the balance of Se during the study is given in Table 5. For the initial $10 \mathrm{~d}$, the subjects were in positive balance by a total of +260 (SE 29) $\mu \mathrm{g}$. After institution of the restriction phase, their balance became negative relatively rapidly, at a loss of about $17-18 \mu \mathrm{g} / \mathrm{d}$. At the end of the study, the subjects had only a small negative balance. Levander et al. (1981) reported that during the first $12 \mathrm{~d}$ after initiation of the Se-restriction period a negative balance of $-35 \mu \mathrm{g} / \mathrm{d}$ was observed which was reduced to $-21 \mu \mathrm{g} / \mathrm{d}$ for days $13-45$ of their study. Our value of -17 (SE 2) $\mu \mathrm{g} / \mathrm{d}$ is similar to their observation. For the final phase of the experiment (days 38-45) the reduced negative balance may, of course, be in part due to ingestion of the relatively large dose of the stable isotope (200 $\mu \mathrm{g} \mathrm{Se})$ on day 39 of the study.

During the initial $29 \mathrm{~d}$ of the Se-restriction period (days 11-39), our subjects consumed a total of $331 \mu \mathrm{g}$ Se and excreted (faecal + urinary) 1071 (SE 66) $\mu \mathrm{g}$ resulting in a net loss of 740 (SE 66) $\mu \mathrm{g}$. Levander et al. (1981) observed a net total loss of $707 \mu \mathrm{g}$ Se during the last $33 \mathrm{~d}$ of their Se-restriction period with the daily average for a $45 \mathrm{~d}$ restriction period being 25 (SE 6) $\mu \mathrm{g} / \mathrm{d}$. Again our values amounted to 26 (SE 2) $\mu \mathrm{g} / \mathrm{d}$, in excellent agreement with those of Levander et al. (1981). Of course, the real total loss was perhaps significantly larger than these values because of the obligatory losses via sweat, skin, etc., which were not measured.

It is difficult to assess the significance of this negative balance in relation to body stores 


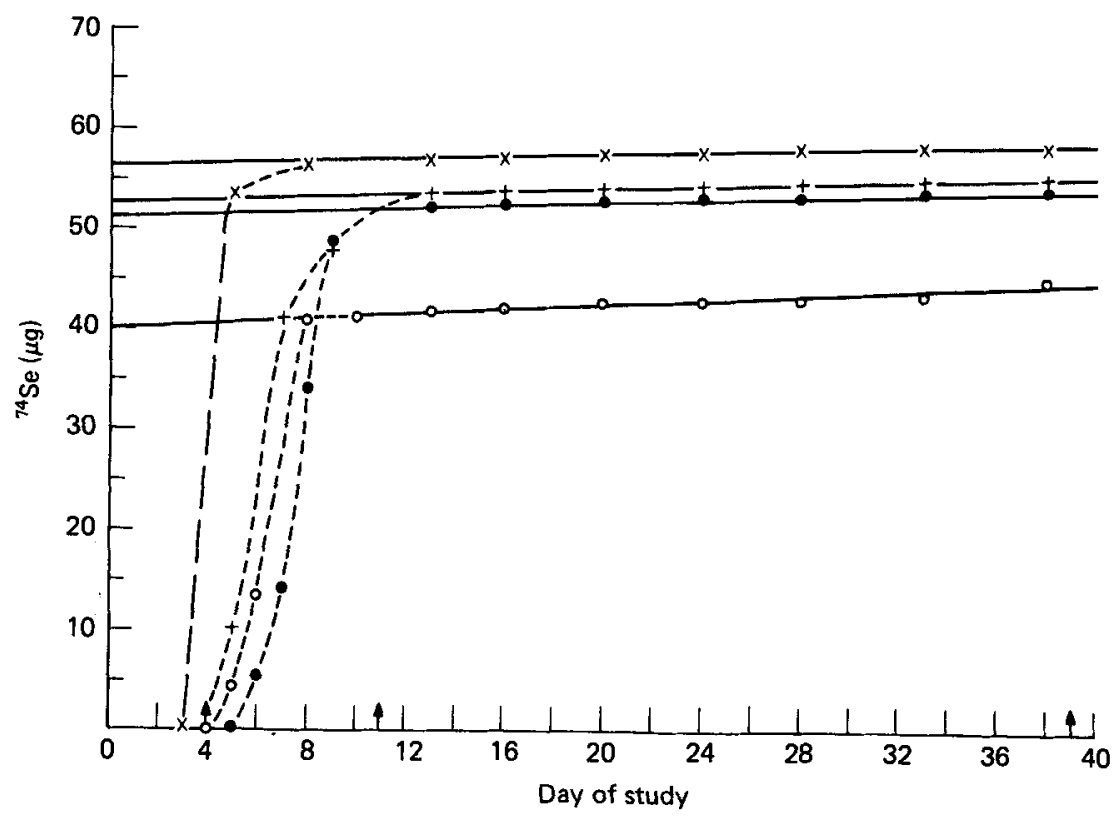

Fig. 3. Cumulative faecal excretion ( $\left.\mu \mathrm{g}^{74} \mathrm{Se}\right)$ of enriched selenium, first administered on day 4 of the study, in four $(O, O, x,+)$ adult male human subjects during periods of adequate-(days 1-10) and low-(days 11-45) Se intake. For values of re-entry calculated from linear regression of the plateau portion of each cumulative plot, see below (gastrointestinal absorption and endogenous secretion). Arrows indicate (from left to right): administration of first dose of ${ }^{74} \mathrm{Se}$, initiation of Se-restriction phase, administration of second dose of ${ }^{74}$ Se.

because of lack of reliable information on Se pool sizes and their turnovers. We have attempted to employ the concept of isotope dilution with stable isotope methodology (Janghorbani et al. 1984) to arrive at some estimates for these factors. We estimate that the pool size exchanging with a dose of ${ }^{74} \mathrm{SeO}_{3}{ }^{2-}$ would increase rapidly during the first month of the present study, reaching an exchangeable pool size of about $10 \mathrm{mg}$ (in about $1 \mathrm{month}$ ). This is on the lower side but in reasonable agreement with the range of $13 \cdot 0-20 \cdot 3 \mathrm{mg}$ given by Schroeder et al (1970) based on tissue analysis of (presumably American) carcasses. More importantly, however, we estimate the rate of this exchange to decrease rapidly from the initial value of about 50 to $2.5 \mu \mathrm{g} / \mathrm{h}$ after $30 \mathrm{~d}$. Comparison of the size of the expanding pool with the Se content of anatomic organs indicates that after about $25 \mathrm{~h}$ the exchangeable pool size corresponds roughly to the expected Se pool size for plasma and liver combined.

\section{Isotopic studies}

The balance results clearly show that, following Se restriction, both faecal and urinary excretion were reduced. However, the role of the gastrointestinal tract cannot be elucidated in response to this restriction because of the unknown contribution of dietary Se to the faecal pool. In addition, it is not clear whether the general decrease in urinary Se excretion is contributed to by the decrease in excretion of newly absorbed Se or mobilization of body pools. Isotopic values help elucidate selected aspects of these issues.

Gastrointestinal absorption and endogenous secretion. The faecal excretion curves for the label following its ingestion on day 4 of the study are given in Fig. 3. All results yielded a highly-correlated linear positive slope for the last seven values with estimated re-entry rates $(\mu \mathrm{g} / \mathrm{d}$ ) of 0.0621 (subject 01 ), $0 \cdot 118$ (subject 02 ), 0.0736 (subject 03 ) and 0.0745 (subject 
Table 6. Fractional absorption of ${ }^{74} \mathrm{SeO}_{3}{ }^{2-}$ by adult male human subjects during periods of adequate- and low-Se intake

\begin{tabular}{cccc} 
& \multicolumn{3}{c}{ Fractional absorption } \\
& \multicolumn{2}{c}{ Adequate-Se intake } & Low-Se intake \\
\cline { 2 - 4 } & Method $1^{*}$ & Method $2 \dagger$ & Method 2 \\
no. & 0.479 & 0.470 & 0.486 \\
01 & 0.627 & 0.618 & 0.637 \\
02 & 0.527 & 0.523 & 0.568 \\
03 & 0.513 & 0.503 & 0.478 \\
04 & $0.536(0.032)$ & $0.529(0.032)$ & $0.542(0.038)$ \\
\hline
\end{tabular}

* Lutwak's (1969) method.

$\dagger$ Five-stool faecal-pooling method (Janghorbani et al. 1981 ) ).

04). These findings yield endogenous faecal losses for the $34 \mathrm{~d}$ of the study (as percentage of dose) of 1.9-3.7 which is somewhat lower than the 3-4\% estimated for $14 \mathrm{~d}$ for New Zealand women by Stewart et al. (1978). In terms of the absorbed dose, these values for the $34-\mathrm{d}$ period are in the range $4 \cdot 1-6.0 \%$, which compares with the corresponding range of $4-6 \%$ over $14 \mathrm{~d}$ reported for New Zealand women (Stewart et al. 1978).

Little accurate information is available on the issue of gastrointestinal losses in American adults, but Jereb et al. (1975), following intravenous administration of ${ }^{75} \mathrm{SeO}_{3}{ }^{2-}$, reported a wide range (12 (SE 8$) \%$ of administered dose $/ 34 \mathrm{~d}$ ) of excretion of radiotracer in the stools. We have also measured faecal excretion of the absorbed label following ingestion of ${ }^{74}$ Se-labelled chicken meat (Christensen, 1982) in eight adult Americans and obtained an average of 22 (SE 3 )\% of absorbed dose $/ 34 \mathrm{~d}$. The subjects in the latter study consumed about $150 \mu \mathrm{g}$ total Se, while in the present study the measurements correspond to the period during which daily intake of Se was only $11.4 \mu \mathrm{g}$. Thus, from these considerations it appears that re-entry of the absorbed isotope was significantly reduced because of institution of Se-restriction. Should this prove to be the case in future studies, it is the first report of gastrointestinal regulation of Se homeostasis in man.

Employing the extrapolation method of Lutwak (1969) (method 1) to correct for re-entry of the absorbed dose, we have determined fractional absorptions during the period of adequate-Se intake and have compared these with the method based on analysis of a pool of five faecal samples (method 2) (Janghorbani et al. 1981 b). The results are given in Table 6. Comparing the two methods, it is clear that in every case method 1 yields absorption values higher than those for the simple five-stool method, as expected. However, the difference between the results from the two methods is small, so that underestimation in absorption resulting from neglect of re-entry of the absorbed dose during the five-stool collection period does not introduce a sufficiently large error to warrant institution of the more cumbersome method for general use. Comparing fractional absorption, both calculated with method 2, between the two phases the hypothesis $(\mathrm{H}: \mathrm{d} 0)$ is accepted at $\alpha 0.05(\mathrm{~T} 0.951$, $\left.t_{0 \cdot 025,3} 3 \cdot 12\right)$. Thus despite the apparently larger values in three of the four subjects during the period of low-Se intake, we conclude that short-term Se-restriction did not influence fractional gastrointestinal absorption of a single dose of ${ }^{74} \mathrm{SeO}_{3}{ }^{2-}$.

Urinary excretion. The dynamics of urinary excretion during the period of low-Se intake are compared in Fig. 4 for $(a)$ daily unenriched component of urinary Se, $(b)$ daily excretion of the absorbed ${ }^{74} \mathrm{Se}$ label, (c) MIR in daily urine output. Following administration of this relatively large dose $(200 \mu \mathrm{g} \mathrm{Se})$, there appeared to be a steady decline in urinary output of 

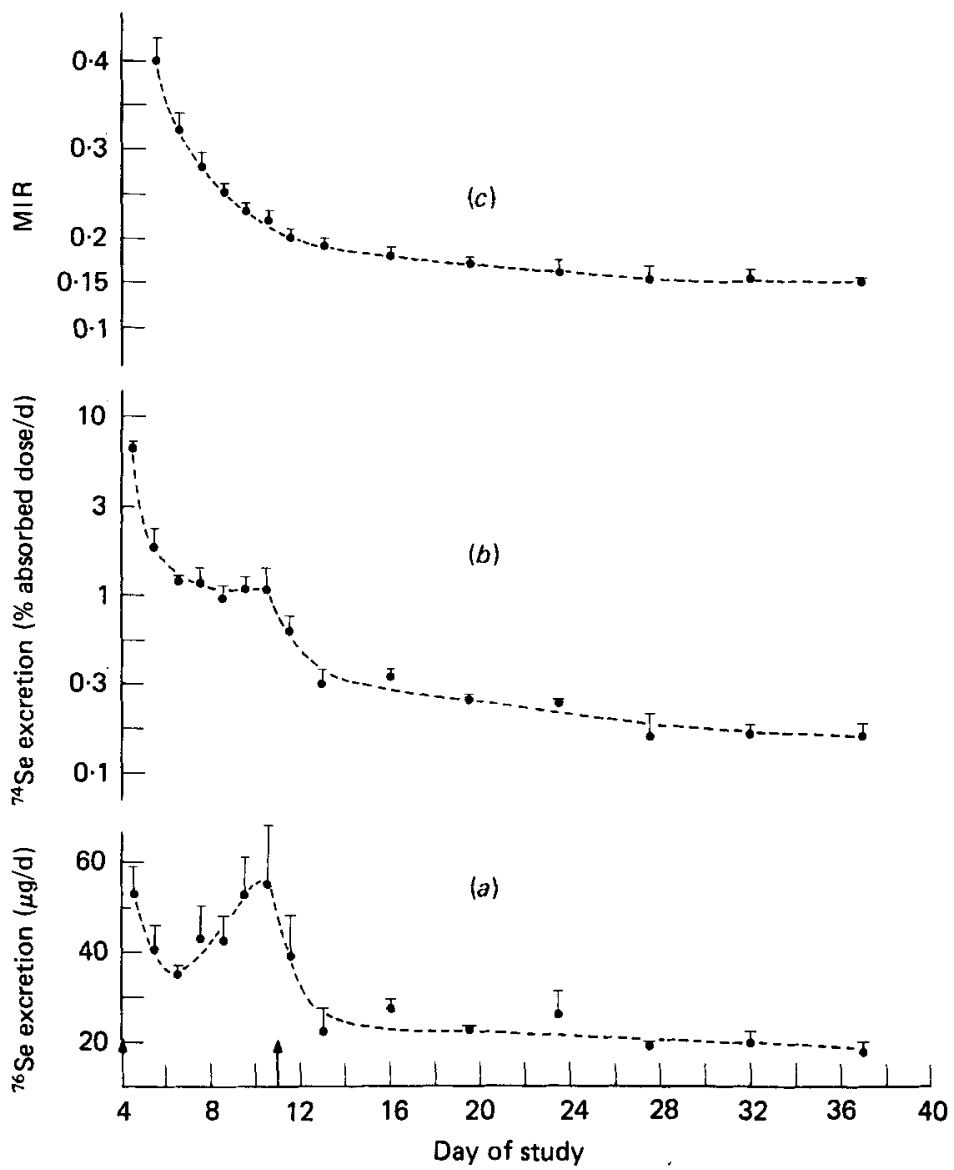

Fig. 4. Dynamics of urinary excretion of ${ }^{74} \mathrm{Se}$ in four adult male human subjects during periods of adequate(days 1-10) and low- (days 11-45) Se intake. Values are means with their standard errors represented by vertical bars for four men. Arrows indicate (left to right): administration of first dose of ${ }^{74} \mathrm{Se}$, initiation of Se-restriction phase. (a) Daily unenriched component of urinary Se, $(b)$ daily excretion of absorbed ${ }^{74} \mathrm{Se}$ label, (c) mass isotope ratio ( ${ }^{74} \mathrm{Se}:{ }^{76} \mathrm{Se}$; MIR) in daily urine output. Note the sharp discontinuity in $(b)$ but not in $(c)$ corresponding to initiation of the Se-restriction phase.

the unenriched component of Se for the following $2-3 \mathrm{~d}$; thereafter the daily excretion appeared to be increasing until the start of the Se-restriction phase. During this first period, and except for the day of isotope administration, the subjects consumed about $108 \mu \mathrm{g} \mathrm{Se}$ daily. Thus, we would expect their urinary excretion to be constant. It is not clear why Se excretion appeared to vary in a periodic and non-random fashion (Fig. $4 a$ ). After initiation of the Se-restriction phase, the unenriched component of total Se excretion decreased rapidly during the following few days, thereafter gradually stabilizing in a manner consistent with the observations of Levander et al. (1981).

The isotope-excretion curve (Fig. $4 b$ ) followed the expected exponential decay pattern starting at 6.6 (SE 0.7) \% absorbed dose for the first day following ingestion of the isotope and decreasing to 1.07 (SE 0.3 ) \% absorbed dose/d immediately before initiation of the restriction phase. The rate of change in daily excretion of the isotope decreased rapidly and appeared close to zero between days 4 and 6 following ingestion of the isotope. This pattern is similar to the results of Swanson et al. (1983), who gave adult women egg yolk and egg 


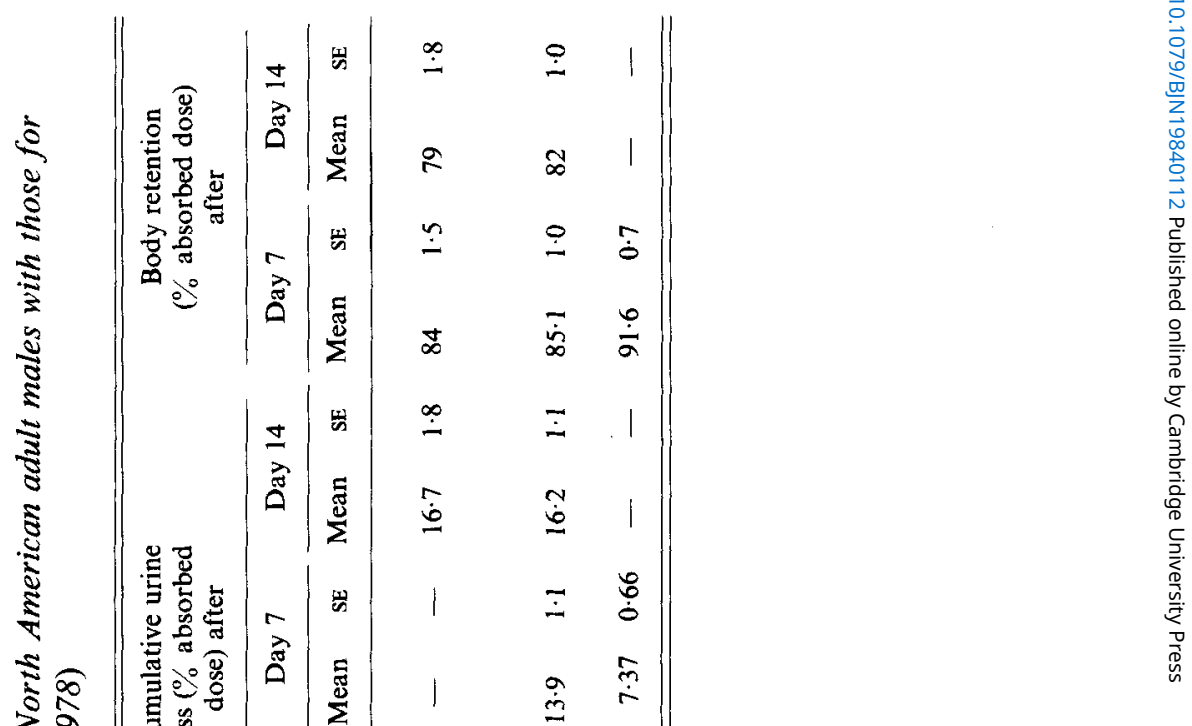

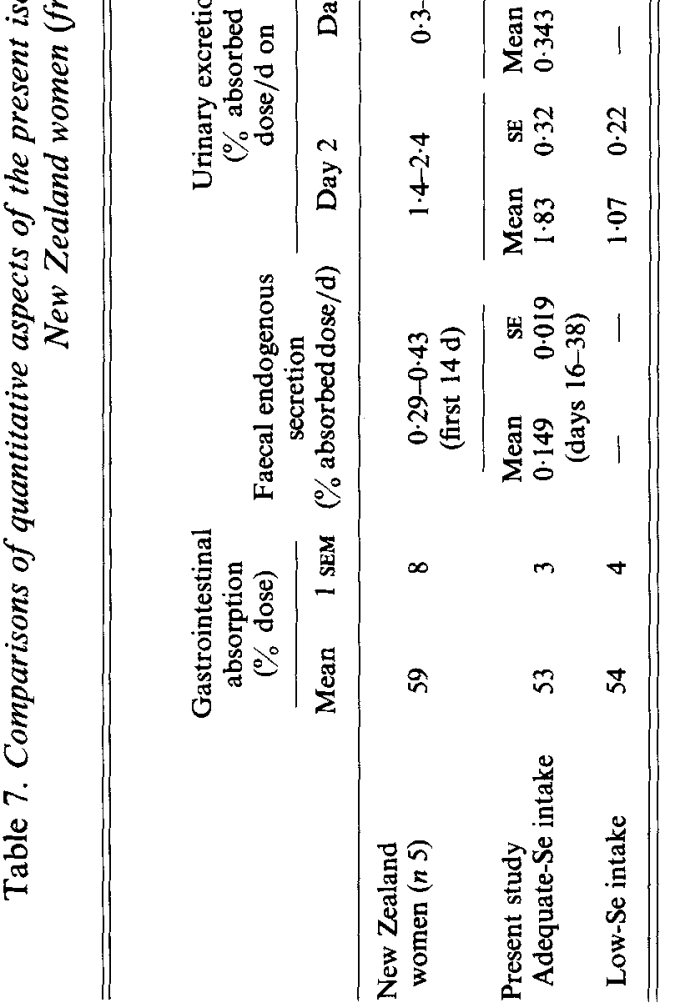


white that had been intrinsically labelled with ${ }^{76} \mathrm{Se}$. Immediately on institution of the reduced dietary intake, a sharp discontinuity in the isotope excretion was observed reflecting homeostatic response to the reduced intake. However, the MIR curve (Fig. $4 c$ ) did not show a pronounced discontinuity on day 7 (initiation of Se-restriction phase). This was unexpected since we had anticipated a significant portion of urinary Se to be of dietary origin. Should this have been the case, there would have been a correspondingly pronounced increase in the MIR reflecting the absence of the dietary component of the unenriched Se. Thus, our observations indicate that the major portion of urinary Se is not of direct dietary origin. Our results indicate that during the first $24 \mathrm{~h}$ post-ingestion, an average of $6.6(\mathrm{SE} 0.7) \%$ of the absorbed dose was excreted in the urine (Fig. $4 \mathrm{~b}$ ), amounting to 8.5 (SE 0.8$) \%$ for the $48 \mathrm{~h}$ post ingestion. If we accept that, after the initial $48 \mathrm{~h}$ following ingestion of the dose, excretion of the absorbed isotope was indistinguishable from native plasma Se (Janghorbani et al. 1981a) then, on average, no more than $7 \mu \mathrm{g}$ urinary Se originated from the dietary intake of the preceding $24 \mathrm{~h}(6.6 \%$ of $200 \mu \mathrm{g}$ administered dose). Thus, for a daily urinary excretion of 46 (SE 3) $\mu \mathrm{g}$ for total Se (average of observed values for days $1-7$, Fig. $4 a$ ), this amounted to only $15 \%$ of total daily urinary Se. Therefore, the major portion of urinary Se must have undergone a significant reprocessing by the body compartments before excretion in the urine and not be of direct dietary origin.

We have compared the quantitative aspects of our isotopic component of the present study with that reported for New Zealand women by Stewart et al. (1978) in Table 7. They observed intestinal absorption of 59 (SE 8$) \%$ of the dose and this compares with our values (mean with SE) of 53 (3) and 54 (4) for the Se-adequate and Se-restricted phases. The calculated endogenous re-entry of $0 \cdot 149$ (SE 0.019 ) of our study compares with their reported range of 0.29 ( $\mathrm{SE} 0.43$ ). As noted before, our study seems to indicate that this rate is perhaps lower than should be expected under dietary intake conditions typical of North Americans and may have been influenced significantly as a result of dietary restriction. Urinary excretion of the absorbed isotope during the first $48 \mathrm{~h}$ of our study was 1.83 (SE 0.32 ) $\%$ absorbed dose/d during the period of adequate Se intake, which compares favourably with the range of 1.4-2.4 reported for New Zealand women (Stewart et al. 1978). However, during the period of low Se intake, the $48 \mathrm{~h}$ urinary excretion (1.07 (SE 0.22)\%) was less than that reported for New Zealanders (Stewart et al. 1978), as was our value of 0.343 (SE 0.015) at day 14 in comparison with their reported range of $0 \cdot 3-0.68$. Thus, it appears that immediate excretion of dietary Se in urine was quantitatively similar in our subjects and the New Zealand women studied by Stewart et al. (1978), and that the major differences in urinary Se excretion between the two subject groups must be of body origin. We have estimated the selenite-exchangeable body pool size of our subjects to be about $10 \mathrm{mg}$ (Janghorbani et al. 1984), which is roughly threefold that of New Zealanders (Stewart et al. 1978), so that our suggestion of a body-Se source for urinary Se appears consistent with the expected differences in the body Se status of the two subject groups. We estimate that the 7-d body retention of our subjects was (mean with SE) 85.1 (1) and $91.6(0.7) \%$ absorbed dose which compares with the value of $84(1 \cdot 5) \%$ for the New Zealand women (Stewart et al. 1978). The higher values observed in our study must be a consequence of institution of Se restriction.

Quantitative comparisons between the present study and that of Stewart et al. (1978) seem to indicate that the quantitative aspects of absorption, excretion and retention of dietary selenite are similar between the two subject groups under these experimental conditions. The major differences are then related to the lifelong accumulation of a greater body burden of Se in Americans as compared with New Zealanders. 
This work was carried out in part with support from PHS Grant No. 1-RO1-CA-27919. The authors are also grateful to the staff of the MIT Nuclear Reactor Laboratory and the Clinical Research Center for their assistance in various phases of the study.

\section{REFERENCES}

Chen, Xi, Chen, Xu, Yang, G., Wen, Z., Chen, J. \& Ge, K. (1981). In Selenium in Biology and Medicine, pp. 171-175 [J. E. Spallholz, J. L. Martin and H. E. Ganter, editors]. Westport, CT, USA: AVI Publishing Co.

Christensen, M. J. (1982). Application of stable isotope in the study of selenium bioavailability in man. PhD Thesis, Massachusetts Institute of Technology.

Dickson, R. C. \& Tomlinson, R. N. (1967). Clinical Chimica Acta 16, 311-321.

Janghorbani, M., Christensen, M. J., Nahapetian, A. \& Young V. R. (1981a). American Journal of Clinical Nutrition 35, 647-654.

Janghorbani, M., Kasper, L. J. \& Young, V R. (1984). American Journal of Clinical Nutrition (In the Press). Janghorbani, M., Ting, B. T. G., Nahapetian, A. \& Young, V. R. (1982). Analytical Chemistry 54, 1188-1190. Janghorbani, M., Ting, B. T. G. \& Young, V. R. (1981 b). American Journal of Clinical Nutrition 34, $2816-2830$. Jereb, M., Falk, R., Jereb, B \& Lindhe, C. (1975). Journal of Nuclear Medicine 16, 846-850.

Lederer, C. M., Hollander, J. M. \& Perlman, I. (1967). Table of Isotopes, 6th ed. New York: John Wiley and Sons, Inc.

Levander, O. A., Sutherland, B., Morris, V. C. \& King, J. C. (1981). American Journal of Clinical Nutrition 34, 2662-2669.

Lutwak, L. (1969). American Journal of Clinical Nutrition 22, 771-785.

Schroeder, H. A., Frost, D. V. \& Balassa, J. J. (1970). Journal of Chronic Disease 23, 227-243.

Stewart, R. D. H., Griffiths, N. M., Thomson, C. D. \& Robinson, M. F. (1978). British Journal of Nutrition 40, 45-54.

Swanson, C. A., Reamer, D. C., Veillon, C., King, J. C. \& Levander, O. A. (1983). American Journal of Clinical Nutrition 38, 169-180.

Thomson, C. D. \& Robinson, M. F. (1980). American Journal of Clinical Nutrition 33, 302-323.

Tonsirin, K., Young, V. R., Miller, M. \& Scrimshaw, N. S. (1973). Journal of Nutrition 103, $1220-1228$.

Young, V. R., Nahapetian, A. \& Janghorbani, M. (1982). American Journal of Clinical Nutrition 35, $1076-1088$. 